Pacific Journal of 


\title{
A UNIQUENESS THEOREM FOR EDGE-CHROMATIC GRAPHS
}

\section{J. G. KALBFLEISCH}

\begin{abstract}
Certain of the Ramsey numbers may be evaluated by construction of edge chromatic graphs. The edges of the complete graph on 17 vertices may be coloured in two colours in such a way that no complete subgraph on 4 vertices has all its edges one colour. In this paper it is proved that this colouring is unique.
\end{abstract}

The complete graph on $n$ vertices will be called an $n$-clique. The $\left(\begin{array}{l}n \\ 2\end{array}\right)$ edges of the $n$-clique are painted with red and blue. For $p, q \geqq 2$, a $(p, q)$-colouring is a colouring in which there is no red p-clique (no set of $p$ points interjoined by red lines only) and no blue $q$-clique. A theorem of Ramsey [7] implies the existence of a least integer $M(p, q)$ such that for $n \geqq M$ no $(p, q)$-colouring of the $n$-clique exists. Note that by symmetry $M(p, q)=M(q, p)$.

Obviously, $M(2, q)=q$, but apart from this trivial case, few of these Ramsey numbers are known. Greenwood and Gleason [2] have shown that $M(3,3)=6, M(3,4)=9, M(3,5)=14$, and $M(4,4)=18$. These results are obtained by a different method in [3]. The only other known values are $M(3,6)=18$ (see [4] or [6]), and $M(3,7)=23$ (See [1]).

In order to establish the value of $M(p, q)$, it is necessary to construct a $(p, q)$-colouring of the $(M-1)$-clique. Proof of the existence of such colourings is accomplished in [2] using finite field residue theory, and by means of "regular colourings" in [3]. The uniqueness of these colourings is also of interest. For in a $(p, q+1)$-colouring all points joined by blue lines to a given point must be $(p, q)$-coloured. Similarly, in a $(p+1, q)$-colouring all points joined by red lines to a given point must be $(p, q)$-coloured. When one is discussing the existence of $(p, q+1)$ and $(p+1, q)$-colourings, it is of considerable help to know what $(p, q)$-colourings are possible.

A $(4,4)$-colouring of the 17-clique has been constructed in [2] and [3]. Here it will be proved that this $(4,4)$-colouring is unique.

2. Preliminary results and definitions. Two edge chromatic graphs $G, H$ are said to be isomorphic if there exists a one-to-one mapping $f$ of the vertices of $G$ onto the vertices of $H$ such that for each vertex pair $X, Y$ in $G$, edge $f(X) f(Y)$ in $H$ has the same colour as edge $X Y$ in $G$. A $(p, q)$-colouring $G$ of the $n$-clique is said to be 
unique if every other $(p, q)$-colouring $H$ of the $n$-clique is isomorphic to $G$.

It is easily seen that there is a unique $(3,3)$-colouring of the 5-clique. It contains 5 red lines forming a pentagon. The proof of Lemma 1 is not difficult, and will be found in [4] and [6]. This result has been obtained by others as well-for example, it was known to Greenwood and Gleason in 1961.

LEMMA 1. There are three nonisomorphic $(3,4)$-colourings of the 8-clique with 10,11 and 12 lines, respectively (Figure 1 gives the red lines).

COROLLARY. There are three distinct $(4,3)$-colourings of the 8clique with 18, 17 and 16 red lines (complement of Figure 1 gives the red lines)

Kéry also mentions that there is a unique $(3,5)$-colouring of the 13-clique. A proof of this statement will be found in [4], where lists of all nine $(3,4)$-colouring of the 7 -clique, all twelve $(3,5)$-colourings of the 12-clique, and all seven $(3,6)$-colourings of the 17-clique are also given.
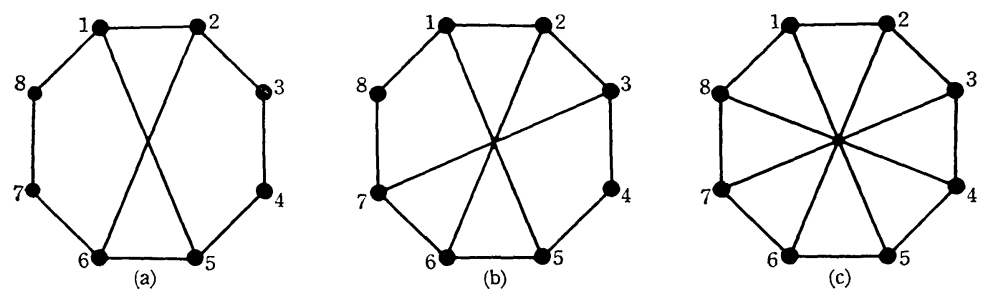

FIgURE 1. $(3,4)$-colourings of the 8-clique.

3. A uniqueness theorem. The result to be proved in this section is the following:

THEOREM. There exists a unique $(4,4)$-colouring of the 17-clique.

The proof of this Theorem is fairly long, and will be given in a series of Lemmas. In all diagrams, only red lines are drawn in.

LEMMA 2. Let 0 be any point in a $(4,4)$-colouring of the 17clique. Let $\mathscr{P}$ denote the subgraph formed by the $x$ points joined to 0 by red. Let $y$ denote the subgraph formed by the $y$ points joined to 0 by blue. Then $x=y=8$; $\mathscr{X}$ must be coloured as in Figure 2(a), and $\mathscr{Y}$ must be coloured as in Figure 2(b). 
Proof. A red triangle in $\mathscr{X}$ together with 0 would form a red 4-clique. Therefore, $\mathscr{Z}$ is $(3,4)$-coloured, and since $M(3,4)=9, x \leqq 8$. Similarly, $y \leqq M(4,3)-1=8$. Since $x+y+1=17, x=y=8$; all points are 8-valent in red and 8-valent in blue.

The 8-clique $\mathscr{X}$ must be $(3,4)$-coloured. By Lemma $1, \mathscr{X}$ contains at most 12 red lines, and there are at least $8.8-8-2.12=32$ red lines from $\mathscr{X}$ to $\mathscr{Y}$. Therefore, $\mathscr{Y}$ contains at most $(8.8-32) / 2=16$ red lines. However, $\mathscr{Y}$ is $(4,3)$-coloured, and by the Corollary to Lemma 1 , it contains at least 16 red lines. Therefore, $\mathscr{Y}$ is $(4,3)$ coloured with 16 red lines, and $\mathscr{X}$ is $(3,4)$-coloured with 12 red lines.

Now name the points of $\mathscr{X} A, B, C, \cdots, H$, and the points of $\mathscr{Y}$ $P, Q, \cdots, W$. By Lemma $1, \mathscr{Z}$ is coloured as in Figure 2(a). By the Corollary, the colouring of $\mathscr{Y}$ is given by the complement of Figure 1(c), and it is easy to show that this colouring may be redrawn as in Figure 2(b). This completes the proof of Lemma 2.

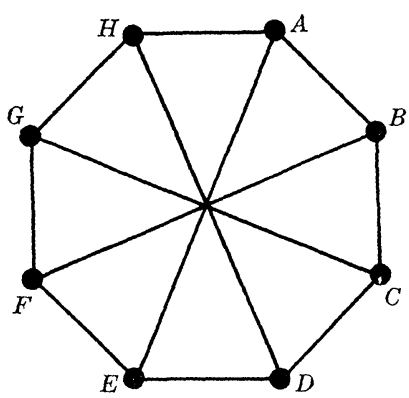

(a)

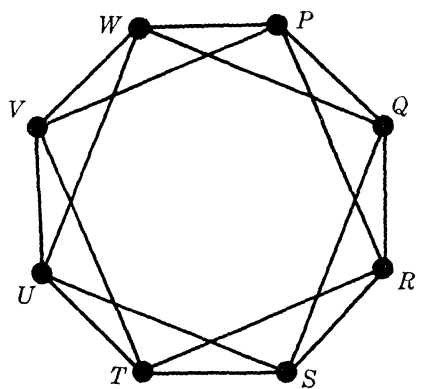

(b)

Figure 2. Diagrams for Lemma 2.

LEMMA 3. Let $I, J$ be two points in a $(4,4)$-colouring of the 17-clique.

(i) If IJ is red, there are three points joined by red lines to both $I$ and $J$, and for points joined by blue lines to both $I$ and $J$.

(ii) If IJ is blue, there are four points joined by red lines to both $I$ and $J$, and three points joined by blue lines to both $I$ and $J$.

Proof. I may be chosen to be 0 in Lemma 2. By symmetry, in (i) $J$ may be taken to be any point in $\mathscr{X}$, while in (ii) $J$ may be any point in $\mathscr{Y}$. Since all points are 8-valent in red, each point of $\mathscr{X}$ is joined by red lines to four points in $\mathscr{Y}$ and conversely. The results of Lemma 3 may now be read from Figure 2 .

Now choose a particular point 1 in a $(4,4)$-colouring of the 17clique. Points joined by red lines to 1 are named $2,3, \cdots, 9$; points joined by blue lines to 1 are named $10,11, \cdots, 17$ (Figure 3). It will be shown that red lines joining points in $2,3, \cdots, 9$ to points in $10,11, \cdots, 17$ may be drawn in essentially one way only. 


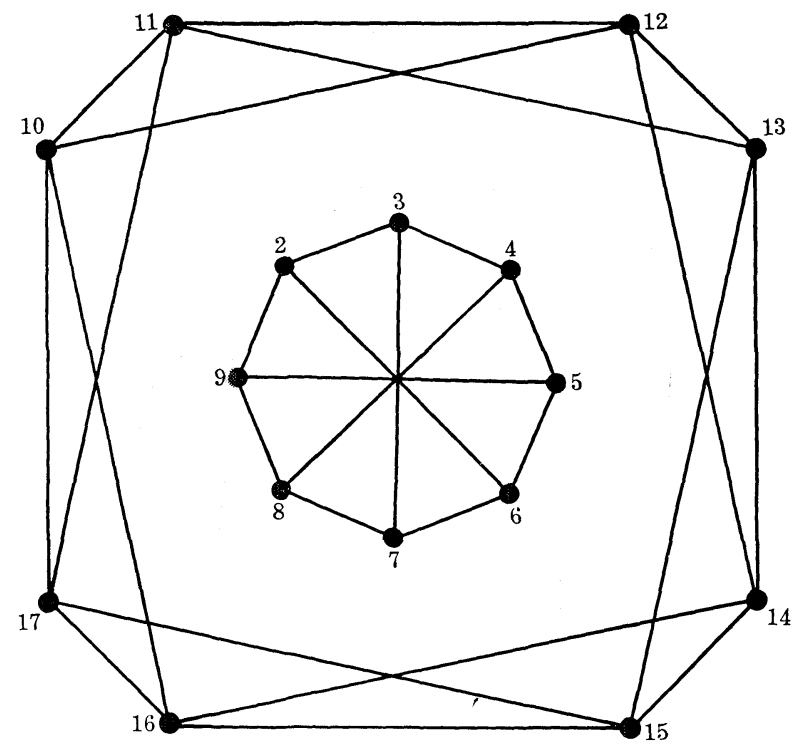

FIGURE 3.

LEMma 4. The four points in $2,3, \cdots, 9$ which are joined to 10 by blue lines form a red path of length 3; the remaining four points of $2,3, \cdots, 9$ are joined to 10 by red lines and also form a red path of length 3 (Figure 3).

Proof. 10 is joined by blue lines to $13,14,15,1$ and to four points in $2,3, \cdots, 9$. This 8-clique must be coloured as in Figure 2(b). $13-14-15$ is a red triangle, and by symmetry in Figure 2(b), $\{13,14,15$,$\} may be identified with \{P, Q, R\}$. (There is only one kind of red triangle in Figure $2(b))$. Now 1 is joined by blue lines to 13,14 and 15 and must correspond to $U$. The four points in $2,3, \cdots, 9$ joined by blue to 10 must correspond to $W V T S$, and they form a red path $W-V-T-S$ of length 3 .

Also, 10 is joined by red lines to $11,12,16$ and 17 plus four

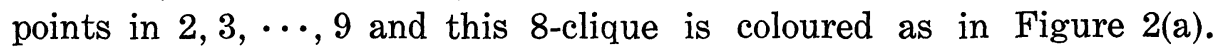
16-17-11-12 is a red path of length 3 in Figure 2(a). By symmetry, $\{11,12,16,17\}$ correspond to $\{H, A, B, C\},\{H, A, B, F\}$, or $\{H, A, E, F\}$. In the first two cases, the remaining four points joined by red lines to 10 correspond to red paths $G-F-E-D$ and $G-C-E-D$, and the lemma holds.

Now suppose $\{11,12,16,17\}$ correspond to $\{H, A, E, F\}$. Then the four points in $2,3, \cdots, 9$ joined to 10 by red lines correspond to $C, D, B, G$, where $C-D, C-B$ and $C-G$ are red. By symmetry in $2,3, \cdots, 9$, take $10-2,10-3,10-6$, and 10-9 red in Figure 3. Now 10-2 is red, and 3,6, and 9 are all joined by red lines to both 2 and 
10. By Lemma 3(i), there is no other point joined by red lines to 10 and 2 both. Therefore, 2 is joined by blue lines to $11,12,16$ and 17 , and 2-13,2-14 and 2-15 are red. Now 2-13-14-15 is a red 4-clique. No $(4,4)$-colouring results in the third case above, and the proof of Lemma 4 is complete.

Lemma 5. For each point $K$ in $10,11, \cdots, 17$, the four points in $2,3, \cdots, 9$ which are joined to $K$ by red lines are numbered $a, a+1, a+2, a+4$, or $a, a+1, a+2, a+6(\bmod 8)$ for some $a=2,3, \cdots, 9$.

Proof. By Lemma 4, the eight points 2,3, $, 9,9$ must be divided into two disjoint red paths of length 3 , one joined to 10 by red lines and the other joined to 10 by blue lines. This can be done in two ways only:

(i) The four points in $2,3, \cdots, 9$ joined by red to 10 are numbered consecutively $(\bmod 8)$

(ii) They are numbered $a, a+1, a+2, a+4$ or $a, a+1, a+2$, $a+6(\bmod 8)$. In either case, 10 (and by symmetry, each point $K$ in $10,11, \cdots, 17)$ is joined by red lines to three consecutive points $a, a+1, a+2$, in $2,3, \cdots, 9$.

Take 10-2, 10-3, 10-4 red. If 2,3 , and 4 are also joined by red lines to another point $L$ in $10,11, \cdots, 17$, Lemma 3 (i) or 3(ii) will be violated. Therefore, each of the 8 sets of three consecutive points $\{2,3,4\},\{3,4,5\}, \cdots,\{9,2,3\}$ is joined by red lines to exactly one point in $10,11, \cdots, 17$. If (i) held, this condition would be violated, and therefore the Lemma holds.

CoRollary. To each $a=2,3, \cdots, 9$ there corresponds a unique $K$ in $10,11, \cdots, 17$ to which $a, a+1$ and $a+2$ (addition mod 8) are joined by red lines.

Proof of theorem. By the corollary above, Table 1 may now be constructed. Four points in a column of the table are all joined by red lines to the same point $K$ in $10,11, \cdots, 17$. The eight sets of three consecutive points may be entered, one in each column. By symmetry, take $10-2,10-3,10-4$ red. Either $10-6$ or $10-8$ is also red by Lemma 5 , and by symmetry in 6 and 8 , take 10-8 red. Since there are no more red lines from 8 , the remaining point in the column with $4,5,6$ cannot be $a+4=8$, and must be $a+6=2$. Similarly, there are no more red lines from 2 , and the column with $6,7,8$ must contain 4 ; the column with $8,9,2$ must contain 6 . 
TABLE 1. Red lines in Figure 3.

\begin{tabular}{l||c|c|c|c|c|c|c|c}
\hline \multicolumn{1}{c|}{$K$} & 10 & & & & & & & \\
\hline Points & 2 & 3 & 4 & 5 & 6 & 7 & 8 & 9 \\
Joined & 3 & 4 & 5 & 6 & 7 & 8 & 9 & 2 \\
to $K$ by & 4 & 5 & 6 & 7 & 8 & 9 & 2 & 3 \\
Red lines & 8 & & 2 & & 4 & & 6 &
\end{tabular}

By Lemma 3(i), 10 and 11 are both joined by red lines to one

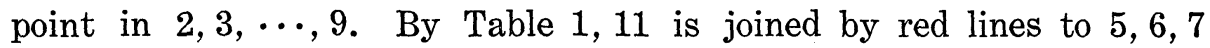
or to $7,8,9$. The same comment applies to 17 . But the graph is symmetrical with respect to 11 and 17 (only red lines from 10 have been specified). Therefore, join 11 by red lines to $5,6,7$, and 17 by red lines to $7,8,9$ (Table 2).

TABLE 2. Red lines in Figure 3.

\begin{tabular}{l||c|c|c|c|c|c|c|c}
\hline \multicolumn{1}{c|}{$K$} & 10 & 13 & 16 & 11 & 14 & 17 & 12 & 15 \\
\hline Points & 2 & 3 & 4 & 5 & 6 & 7 & 8 & 9 \\
Joined & 3 & 4 & 5 & 6 & 7 & 8 & 9 & 2 \\
to $K$ by & 4 & 5 & 6 & 7 & 8 & 9 & 2 & 3 \\
Red lines & 8 & 9 & 2 & 3 & 4 & 5 & 6 & 7
\end{tabular}

Now 10 and 17 are joined by red lines to 11,16 , and 8 . By Lemma 3(i), there is no additional point joined by red lines to both 10 and 17 , and thus $17-3$ is blue. By Lemma $5(a=7), 17-5$ is red. There are no more red lines from 5 , and by Lemma $5(\alpha=9), 7$ may be entered in the 9-2-3 column of Table 2. Similarly, 9 and 3 may be entered in the second and fourth columns of Table 2 .

By Lemma 3(i), there is just one point in $2,3, \cdots, 9$ joined by red lines to both 11 and 12 . Therefore, 12 must be entered above the seventh column of Table 2. Similarly, 13, 14, 15 and 16 must head columns $2,5,8$ and 3 .

The configuration of red lines specified by Figure 3 and Table 2, together with 1 and red lines from it, provide the only possibility for a $(4,4)$-colouring of the 17 -clique. Since a $(4,4)$-colouring is known to exist (see [2] and [3]) one has been constructed above; and its uniqueness is now established.

4. Further results. It is easy to show (as in Lemma 2) that points in a $(4,4)$-colouring of the 16-clique are 7 -valent in red and 8-valent in blue (type $A$ ), or 8-valent in red and 7 -valent in blue (type $B$ ). If there are $a A^{\prime} \mathrm{s}$ and $b B^{\prime} \mathrm{s}$, then $a+b=16$. The number of red lines is $(7 a+8 b) / 2$, so that $a$ and $b$ must both be even.

If 1 and all lines from it are removed from the $(4,4)$-colouring 
of the 17-clique, a $(4,4)$-colouring of the 16-clique with $a=b=8$ is obtained. This colouring has the property that changing the colour of any line introduces a 4-clique of one colour. This suggests that every $(4,4)$-colouring of the 16-clique may have $a=b=8$. At present, all that is known is that there exists no $(4,4)$-colouring of the 16-clique with $a=0$ or $b=0$, which may be proved by arguments similar to those in $\S 3$ (see [4], Chapter 6). Investigation of the remaining cases appears to be a necessary preliminary to evaluating $M(4,5)$. At present it is known only that $25 \leqq M(4,5) \leqq 30$. These bounds are obtained in [3] and [5].

\section{REFERENCES}

1. Jack E. Graver and James Yackel, Some graph theoretic results associated with Ramsey's theorem, 1967 (mimeographed).

2. R. E. Greenwood and A. M. Gleason, Combinatorial relations and chromatic graphs, Canad. J. Math. 7 (1955), 1-7.

3. J. G. Kalbfleisch, Construction of special edge-chromatic graphs, Canad. Math. Bull. 8 (1965), 575-584.

4. Chromatic graphs and Ramsey's theorem, Ph. D. Thesis, University of Waterloo, January, 1966.

5. - Upper bounds for some Ramsey numbers, (to appear in the Journal of Combinatorial Theory).

6. G. Kéry, Ramsey egy gráfélmeleti tétéleröl, Matematikai Lapok 15 (1964), 204-224. 7. F. P. Ramsey, On a problem of formal logic, Proc. London Math. Soc. (2) 30 (1930), 264-286.

Received February 7, 1966.

UNIVERSITY OF WATERLOO 



\section{PACIFIC JOURNAL OF MATHEMATICS}

\section{EDITORS}

\section{H. SAMELSON}

Stanford University

Stanford, California

\author{
J. P. JANS \\ University of Washington \\ Seattle, Washington 98105
}

\section{J. DuGUNDJI}

University of Southern California

Los Angeles, California 90007

RichaRd ARENS

University of California

Los Angeles, California 90024

\section{ASSOCIATE EDITORS}

E. F. BECKENBACH
B. H. NeUManN

F. WOLF

K. YOSIDA

\section{SUPPORTING INSTITUTIONS}

UNIVERSITY OF BRITISH COLUMBIA

CALIFORNIA INSTITUTE OF TECHNOLOGY

UNIVERSITY OF CALIFORNIA

MONTANA STATE UNIVERSITY

UNIVERSITY OF NEVADA

NEW MEXICO STATE UNIVERSITY

OREGON STATE UNIVERSITY

UNIVERSITY OF OREGON

OSAKA UNIVERSITY

UNIVERSITY OF SOUTHERN CALIFORNIA
STANFORD UNIVERSITY

UNIVERSITY OF TOKYO

UNIVERSITY OF UTAH

WASHINGTON STATE UNIVERSITY

UNIVERSITY OF WASHINGTON

AMERICAN MATHEMATICAL SOCIETY

CHEVRON RESEARCH CORPORATION

TRW SYSTEMS

NAVAL ORDNANCE TEST STATION

Mathematical papers intended for publication in the Pacific Journal of Mathematics should be typewritten (double spaced). The first paragraph or two must be capable of being used separately as a synopsis of the entire paper. It should not contain references to the bibliography. Manuscripts may be sent to any one of the four editors. All other communications to the editors should be addressed to the managing editor, Richard Arens at the University of California, Los Angeles, California 90024.

50 reprints per author of each article are furnished free of charge; additional copies may be obtained at cost in multiples of 50 .

The Pacific Journal of Mathematics is published monthly. Effective with Volume 16 the price per volume ( 3 numbers) is $\$ 8.00$; single issues, $\$ 3.00$. Special price for current issues to individual faculty members of supporting institutions and to individual members of the American Mathematical Society: $\$ 4.00$ per volume; single issues $\$ 1.50$. Back numbers are available.

Subscriptions, orders for back numbers, and changes of address should be sent to Pacific Journal of Mathematics, 103 Highland Boulevard, Berkeley 8, California.

Printed at Kokusai Bunken Insatsusha (International Academic Printing Co., Ltd.), No. 6, 2-chome, Fujimi-cho, Chiyoda-ku, Tokyo, Japan.

PUBLISHED BY PACIFIC JOURNAL OF MATHEMATICS, A NON-PROFIT CORPORATION

The Supporting Institutions listed above contribute to the cost of publication of this Journal, but they are not owners or publishers and have no responsibility for its content or policies. 


\section{Pacific Journal of Mathematics}

\section{Vol. 21, No. $3 \quad$ BadMonth, 1967}

Richard Allen Askey, A transplantation theorem for Jacobi coefficients . . . 393

Raymond Balbes, Projective and injective distributive lattices .......... 405

Raymond Balbes and Alfred Horn, Order sums of distributive lattices . . . . 421

Donald Charles Benson, Nonconstant locally recurrent functions ........ 437

Allen Richard Bernstein, Invariant subspaces of polynomially compact operators on Banach space ............................... 445

Robert F. Brown, Fixed points and fibre ................... 465

David Geoffrey Cantor, On the Stone-Weierstrass approximation theorem for valued fields ................................ 473

James Walton England, Stability in topological dynamics .............. 479

Alessandro Figà-Talamanca and Daniel Rider, A theorem on random

Fourier series on noncommutative groups.................. 487

Sav Roman Harasymiv, A note of dilations in $L^{p} \ldots \ldots \ldots \ldots \ldots \ldots . \ldots 493$

J. G. Kalbfleisch, A uniqueness theorem for edge-chromatic graphs ....... 503

Richard Paul Kelisky and Theodore Joseph Rivlin, Iterates of Bernstein polynomials .................................... 511

D. G. Larman, On the union of two starshaped sets ............... 521

Henry B. Mann, Josephine Mitchell and Lowell Schoenfeld, Properties of differential forms in $n$ real variables ...................... 525

John W. Moon and Leo Moser, Generating oriented graphs by means of team comparisons .

Veikko Nevanlinna, A refinement of Selberg's asymptotic equation ...

Ulrich Oberst, Relative satellites and derived functors of functors with additive domain ..............................

John Vincent Ryff, On Muirhead's theorem...............

Carroll O. Wilde and Klaus G. Witz, Invariant means and the Stone-Čech compactification 